\title{
BLOOD-PLATELETS AND TUBERCULOSIS *
}

\author{
GERALD B. WEBB, M.D., GEORGE BURTON GILBERT, M.D. \\ AND \\ LEON C. HAVENS, M.A. \\ COLORADO SPRINGS, COLO.
}

So little is known concerning blood-platelets, and so little interest has been taken in them, that their description by Adami and Nichols ${ }^{1}$ is almost fully quoted.

If only because they play so important a part in the process of thrombosis it is necessary to have a clear understanding regarding the blood-platelets, or, more accurately, regarding what is known concerning their origin.

Apart from this, since the advent of the Romanowsky stain and its modifications, they have of late years come in for increasing recognition.

There is no longer any disposition to regard them as artefacts, but there is still dispute as to their exact significance and as to their unity or duality.

They are small bodies of varying size, in general about $2 \mu$ in diameter, oval or pear-shaped, evidently labile, and varying in shape with slight compression by neighboring cells or platelets, tending to be present in smears in small groups (possibly as the result of rapid agglutination in shed blood).

They are non-nucleated although containing often fine, central granules, which assume a redder tint with the Romanowsky stain in contrast to the bluer ground work.

Pratt's careful studies show that they are present in the normal blood in greater numbers than the leukocytes, although the number shows wider variations from 200,000 to 700,000 per c.mm.

Since their discovery and the early papers by Hayem, Bizzozero and Mrs. Ernest Hart, there have been very various views regarding their nature and mode of origin.

1. That they are precipitated globulin (Löwit. Woolbridge).

2. That they are products of disintegration of white corpuscles (Lilienfeld and Zenker).

3. That they are given off from disintegrating red corpuscles (Mono, Klebs and Arnold).

The exquisite preparations made by J. H. Wright of Boston, demonstrate without possibility of doubt that some at least of the platelets, and those most typical, are normally derived from a particular order of cell, namely from the giant cells (megakaryocytes) of the bone-marrow.

These cells give off processes projecting into the lumina of the capillaries, and it is the distal portions of these which become liberated into the blood as platelets. As such they may, as Schimmelbusch was the first to demonstrate, retain some power of ameboid movement, but the mode of their development sets at rest the debate as to the nature of the central staining granules, they in no sense represent a nucleus. . . .

We must admit that in pernicious anemia the platelets are frequently (though not always) diminished in number, and that here there has been observed a lack of giant cells in the bone-marrow.

Submitted for publication June 18, 1914.

* From the Laboratory of Cragmor Sanatorium, Colorado Springs, Colo.

1. Adami and Nichols: Principles of Pathology, 1911. 
In purpura they have at times been found completely absent. We know of no observations on the marrow giant cells in these cases. They are diminished also in typhoid, but increased in myelogenic leukemia and in pneumonia.

Port and Akijama² regard as normal 230,000 to 240,000 bloodplatelets per cubic millimeter, with slight daily variations.

In acute infections (pneumonia, typhoid, scarlet fever) they found diminished numbers during the fever, but a large increase coincident with the drop in temperature. In chronic diseases they found very slight typical changes.

They think the blood-platelets play a part in the immunity processes as carriers of protective substances which are set free on their destruction.

Pagniez ${ }^{3}$ doubts the necessity of platelets being present for blood coagulation, pointing out that lymph will coagulate without these elements. He reviews all the present knowledge of blood-platelets and suggests that some functions attributed to letkocytes may belong to the platelets, pointing out how difficult it is to procure leukocytes free from platelets.

Werbitzki $\mathrm{i}^{4}$ found that the blood of rabbits and horses contained antibodies for anthrax bacilli, which are different from serum bacteriolysin and the bactericidal substances of leukocytes, and which he traced to the platelets, but he found that the blood-platelets of the ox, hog, log and man had no such substance. Werbitzki determined also that the blood-platelets of the above-mentioned animals and man had no bactericidal effect on typhoid bacilli, colon bacilli, staphylococci or the bacilli of dysentery or cholera.

Eminet" has demonstrated that blood-platelets in different infectious diseases possess different and specific affinities for stains.

He calls the blood-platelets Soterozytes, and shows in infection by the diphtheria bacillus, for instance, that these elements do not stain as they do in tuberculosis or scarlet fever cases, and vice versa. He considers therefore that the blood-platelets share in specific immune processes.

Grüber and Futaki ${ }^{\circ}$ showed that the lymph or serum of a rabbit which has been heated to 65 C. (149 F.) can be given strong bactericidal power against anthrax bacilli if mixed with well-washed bloodpletelets (obtained by injecting sterile water under the skin of the rabbit).

2. Port and Akijama: Klinische Untersuchungen über Blutplattchen, Arch. f. klin. Med., cvi, Nos. 3 and 4.

3. Pagniez: Arch. d. mal. du coeur, d. vaisseaux et due sang, January, 1909.

4. Werbitzki: Ztschr. f. Hyg. u. Infections-krankh., 1911, 1xviii, No. 1.

5. Eminet, Charkow: Arch. f. Kinderh., lvii, Nos. 4 and 6.

6. Gruber and Futaki: München. med. Wchnschr., 1907, No. 6. 
Blood-plasma of rabbits and rats is completely without action against these bacilli. They believe the bactericidal power of the serum arises from a substance given to it by the platelets during the coagulation of the blood. This substance given up by the platelets is not thermolabile alexin, but really the same as is found in the serum of rabbits and rats. (Ottolenghi comes to another opinion.)

The platelet extract in physiological salt solution is not bactericidal, and the platelet extract in citrated blood-plasma is not active. (Ottolenghi says this is because the blood-platelets remain unchanged in this fluid and complement will only be freed when they undergo change as in the formation of fibrin or when they are mixed with serum or lymph.)

Blood-platelets were found to increase the bactericidal power of the normal serum of the rabbit, probably because the normal serum has many amboceptors, but not sufficient complement to activate all of them.

In studying the bactericidal power for anthrax bacilli of the leukocytes, Grüber and Futaki found those taken from "congestion lymph" more powerful than others.

The living plasma of the normal rabbit was found to be entirely free from antagonistic power to anthrax bacilli. The protective body gets into the serum only when the blood clots.

They conclude that the bactericidal substance furnished by the platelets to the serum is entirely different from the thermolabile alexin.

Ottolenghi ${ }^{7}$ described the presence of complement in fibrin and found he could reactivate inactive serum and bring back the bactericidal power against certain bacteria by fibrin or its extract in salt solution.

Schneider $^{8}$ first demonstrated the method of procuring pure platelets by fractional centrifugation. He also demonstrated the connection between platelets and the formation of fibrin and blood-clotting.

Schneider also showed the possibilities of reactivating serum with an extract of platelets.

Aynaud $^{9}$ found that animals sensitized with platelets will react with red corpuscles and vice versa.

Aynaud $^{10}$ has noted the high amount of platelet content which is soluble in the solvent of fats, and also has noted the presence of phosphorus. He thinks these fats agree with the peculiar staining qualities of the platelets and their insolubility in the gastric juice, and their

7. Ottolenghi: München. med Wchnschr., 1907, No. 17.

8. Schneider: München. med. Wchnschr., 1907, No. 3.

9. Aynaud: Compt. rend. Soc. de Biol., 1911, No. 37.

10. Aynaud: - Presse méd., April 1, 1914. 
digestion by the pancreatic juice lend argument in favor of a diffused nuclear substance in the element.

Wells ${ }^{\mathrm{i1}}$ says: The blood-platelets are believed to be largely nucleoproteid, but little is known of their actual composition.

It is still undetermined just what part the platelets play in coagulation. Pratt, however, found that the number of platelets bore no relation to the coagulability of the blood, and that lymph which is free from platelets will coagulate.

Welch describes the steps in the formation of a thrombus after injury to the vessel-wall, as follows: First, there is an accumulation of blood-platelets adhering to the wall at the point of injury. Leukocytes which may be present in small numbers at the beginning, rapidly. increase in number, collecting at the margins of the platelet masses and between them. Not until the leukocytes have accumulated does the fibrin appear.

Table 1.-Blood-Platelet Count of Dr. A. Taken at 12 Noon, at Colorado SRrings

\begin{tabular}{|c|c|c|c|}
\hline Date & Platelets & 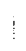 & Leukocytes \\
\hline $\begin{array}{l}4 / 22 / 13 \\
4 / 23 / 13 \\
4 / 25 / 13 \\
4 / 26 / 13 \\
4 / 28 / 13 \\
4 / 29 / 13 \\
4 / 30 / 13 \\
5 / 1 / 13 \\
5 / 2 / 13 \\
5 / 3 / 13 \\
5 / 5 / 13 \\
5 / 6 / 13 \\
5 / 8 / 13 \\
5 / 12 / 13 \\
5 / 14 / 13 \\
5 / 15 / 13 \\
5 / 17 / 13 \\
5 / 20 / 13\end{array}$ & $\begin{array}{l}216.000 \\
184,000 \\
228,000 \\
184.000 \\
216,000 \\
288.000 \\
222,000 \\
180,000 \\
228,000 \\
168,000 \\
228.000 \\
220,000 \\
222,000 \\
164,000 \\
248,000 \\
208.000 \\
244.000 \\
180,000\end{array}$ & : & $\begin{array}{l}6,000 \\
6,000 \\
6,200 \\
6,800 \\
5,800 \\
6,000 \\
6,000 \\
6,000 \\
6,000 \\
6,000 \\
5,400 \\
5,800 \\
6,200\end{array}$ \\
\hline
\end{tabular}

The work to be presented consists of (1) a series of platelet counts in normal adults at sea-level and at an altitude of 6,000 feet; and a series in tuberculous patients and tuberculous animals at various stages, and (2) several series of experiments relative to the possible functions of blood-platelets.

The estimation of blood-platelets per cubic millimeter has until recently been most inexact on account of the lack of suitable technic. In the beginning of this work the metaphosphate method of Pratt was followed.

11. Wells: Chemical Pathology, 1907, p. 264. 
All the counts below enumerated, however, were made according to the technic described by Wright and Kinnicutt. ${ }^{12}$ Two parts of cresyl blue $(1: 300)$ are mixed with three parts of potassium cyanid $(1: 14,000)$ and rapidly filtered, then immediately used to dilute the blood 1:100. The blood must be from a free-flowing drop and the whole procedure must be carried out as quickly as possible.

The method appears reliable judging by the closeness of counts reported for the same individual.

The counts on Dr. A., a normal individual, given in Table 1, show the accuracy of the method which compares favorably with the accuracy of the successive enumerations of the white corpuscles.

Tables 2 and 3 give the counts of blood-platelets on two hundred normal male adults between the ages of 20 and 25 , taken at sea-level (New York) and at an altitude of 6,000 feet (Colorado Springs). All the observations were made at 12 noon, when no digestion was occurring and no unusual exercise had been indulged in.

\section{0,000}
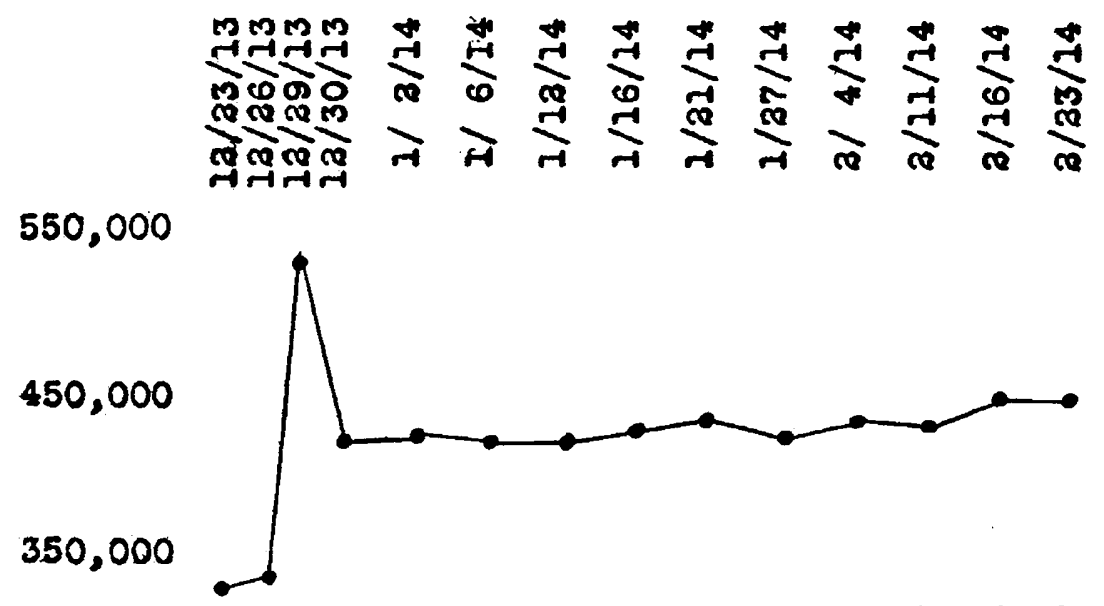

Chart showing composite of blood-platelets in five normal guinea-pigs for a period of two months.

The New York counts were made for us by Dr. Carolyn Rosenberg under the direction of Dr. T. W. Hastings of the Cornell Medical Scinool. Dr. Gilbert and Dr. Rosenberg carefully went over the technic of counting together in New York.

These counts give an average of 302,000 blood-platelets at sea-level and 340,000 at an altitude of 6,000 feet. This is a percentage increase of 12.2 .

The accompanying composite chart shows the average numbers of blood-platelets in five normal guinea-pigs immediately after arrival in

12. Wright, James Homer, and Kinnicutt, Roger: A New Method of Counting the Blood-Platelets for Clinical Purposes, The Journal A. M. A., May 20, 1911 , p. 1457. 
TABle 2.-Blood-Platelet Count Made on Two Hundred Normal Male Adults in New York and Colorado Springs

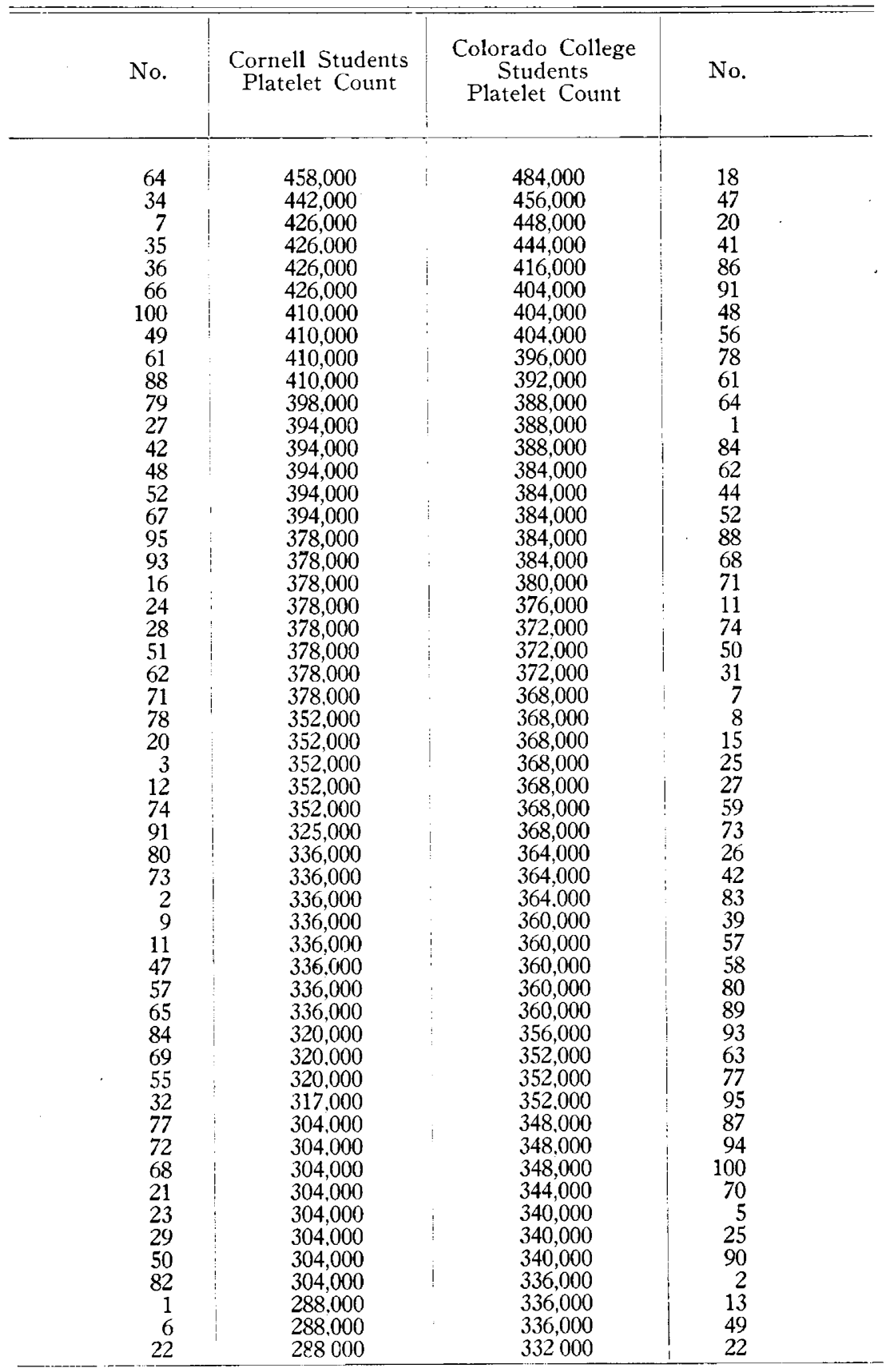


TABLE 2.-(Continued)

\begin{tabular}{|c|c|c|c|}
\hline No. & $\begin{array}{l}\text { Cornell Students } \\
\text { Platelet Count }\end{array}$ & $\begin{array}{c}\text { Colorado College } \\
\text { Students } \\
\text { Platelet Count }\end{array}$ & No. \\
\hline $\begin{array}{r}30 \\
38 \\
59 \\
75 \\
85 \\
89 \\
96 \\
99 \\
70 \\
60 \\
4 \\
8 \\
37 \\
97 \\
90 \\
83 \\
56 \\
53 \\
45 \\
14 \\
18 \\
25 \\
33 \\
43 \\
58 \\
26 \\
54 \\
92 \\
40 \\
63 \\
98 \\
5 \\
87 \\
10 \\
15 \\
19 \\
44 \\
13 \\
31 \\
46 \\
81 \\
41 \\
94 \\
39 \\
76 \\
86 \\
17\end{array}$ & $\begin{array}{l}288,000 \\
288,000 \\
288,000 \\
288,000 \\
288,000 \\
288,000 \\
288,000 \\
272,000 \\
272,000 \\
272,000 \\
272,000 \\
272,000 \\
272,000 \\
256,000 \\
256,000 \\
256,000 \\
256,000 \\
256,000 \\
256,000 \\
256,000 \\
256,000 \\
256,000 \\
24,000 \\
240,000 \\
240,000 \\
240,000 \\
240,000 \\
240,000 \\
224,000 \\
224,000 \\
224,000 \\
224,000 \\
224,000 \\
224,000 \\
224,000 \\
224,000 \\
208,000 \\
208,000 \\
208,000 \\
208,000 \\
192,000 \\
192,000 \\
192,000 \\
192,000 \\
176,000 \\
176,000 \\
160,000\end{array}$ & $\begin{array}{l}332,000 \\
328,000 \\
328,000 \\
328,000 \\
328,000 \\
328,000 \\
324,000 \\
324,000 \\
324,000 \\
324,000 \\
320,000 \\
320,000 \\
320,000 \\
320,000 \\
316,000 \\
316,000 \\
316,000 \\
316,000 \\
312,000 \\
312,000 \\
312,000 \\
312,000 \\
312,000 \\
312,000 \\
308,000 \\
304,000 \\
304,000 \\
300,000 \\
300,000 \\
300,000 \\
292,000 \\
292,000 \\
292,000 \\
288,000 \\
288,000 \\
288,000 \\
284,000 \\
284,000 \\
276,000 \\
272,000 \\
272,000 \\
268,000 \\
268,000 \\
252,000 \\
252,000 \\
252,000 \\
240,000\end{array}$ & $\begin{array}{r}65 \\
14 \\
17 \\
55 \\
79 \\
99 \\
28 \\
45 \\
67 \\
97 \\
3 \\
12 \\
76 \\
81 \\
4 \\
6 \\
19 \\
72 \\
10 \\
33 \\
38 \\
51 \\
82 \\
96 \\
43 \\
9 \\
75 \\
21 \\
32 \\
35 \\
69 \\
66 \\
24 \\
36 \\
46 \\
85 \\
29 \\
98 \\
16 \\
37 \\
53 \\
54 \\
92 \\
30 \\
34 \\
60 \\
40\end{array}$ \\
\hline & $\begin{array}{l}\text { Average, } 302,000 \\
\text { Mean... 288,000 }\end{array}$ & $\begin{array}{l}\text { Average, } 340,000 \\
\text { Mean... 336,000 }\end{array}$ & Pct. Inc., 12.2 \\
\hline
\end{tabular}


Colorado Springs from sea-level and at intervals for two months thereafter.

$\mathrm{We}^{1:}$ have shown elsewhere that blood-platelets were also increased in the circulating blood by (1) carbon monoxid poisoning, (2) hyperemia of the marrow of long bones.

It has been known for some time that blood-platelets were increased in tuberculosis. Our observations both in guinea-pigs and man agree with this.

Other blood-elements are increased as in Table 3.

Tables 4 and 5 show a series of counts on healthy and tuberculous guinea-pigs.

It is especially worthy of notice that not only was a distinct increase in the leukocytes recorded in the tuberculous guinea-pigs, an average of 13,200 per cubic millimeter, as against an average of 7,620 per cubic millimeter for healthy pigs, but also a decided gain in the number of blood-platelets from an average of 438,000 per cubic millimeter in healthy pigs to an average of 622,000 in the tuberculous animals.

\begin{tabular}{|c|c|c|c|}
\hline & $\begin{array}{l}\text { Sea Level } \\
\text { Percentage }\end{array}$ & $\begin{array}{c}\text { Colorado Springs } \\
\text { Percentage }\end{array}$ & $\begin{array}{l}\text { Per Cent. } \\
\text { Increase }\end{array}$ \\
\hline $\begin{array}{l}\text { Lymphocytes } \ldots \ldots \ldots \ldots \\
\text { Hemoglobin } \ldots \ldots \ldots \ldots \\
\text { Red Corpuscles } \ldots \ldots \ldots\end{array}$ & $\begin{array}{c}36 \\
100 \\
5,000,000\end{array}$ & $\begin{array}{c}43 \\
110 \\
6,000,000\end{array}$ & $\begin{array}{l}19.3 \\
10.0 \\
20.0\end{array}$ \\
\hline
\end{tabular}

We have divided the counts on tuberculous patients into the following classes :

1. Early a febrile tuberculosis, 45 counts ; 35 patients ; 368,000 bloodplatelet average.

2. Advanced quiescent tuberculosis, 50 counts ; 40 patients ; 412,000 blood-platelet average.

3. Advanced active tuberculosis, 26 counts; 22 patients; 496,000 blood-platelet average.

The observations on children with measles, given in Table 6 , are of considerable interest.

It is at once seen that a decrease of platelets takes place during the disease.

Only further observations can determine whether the low platelet count may be connected with the high incidence of tuberculosis after measles.

13. Webb, Gilbert and Havens: Colorado Med., January, 1914. 
Table 4.-Blood-Platelet Count in Normal Guinea-Pigs at Colorado SPRINGS, Colo.

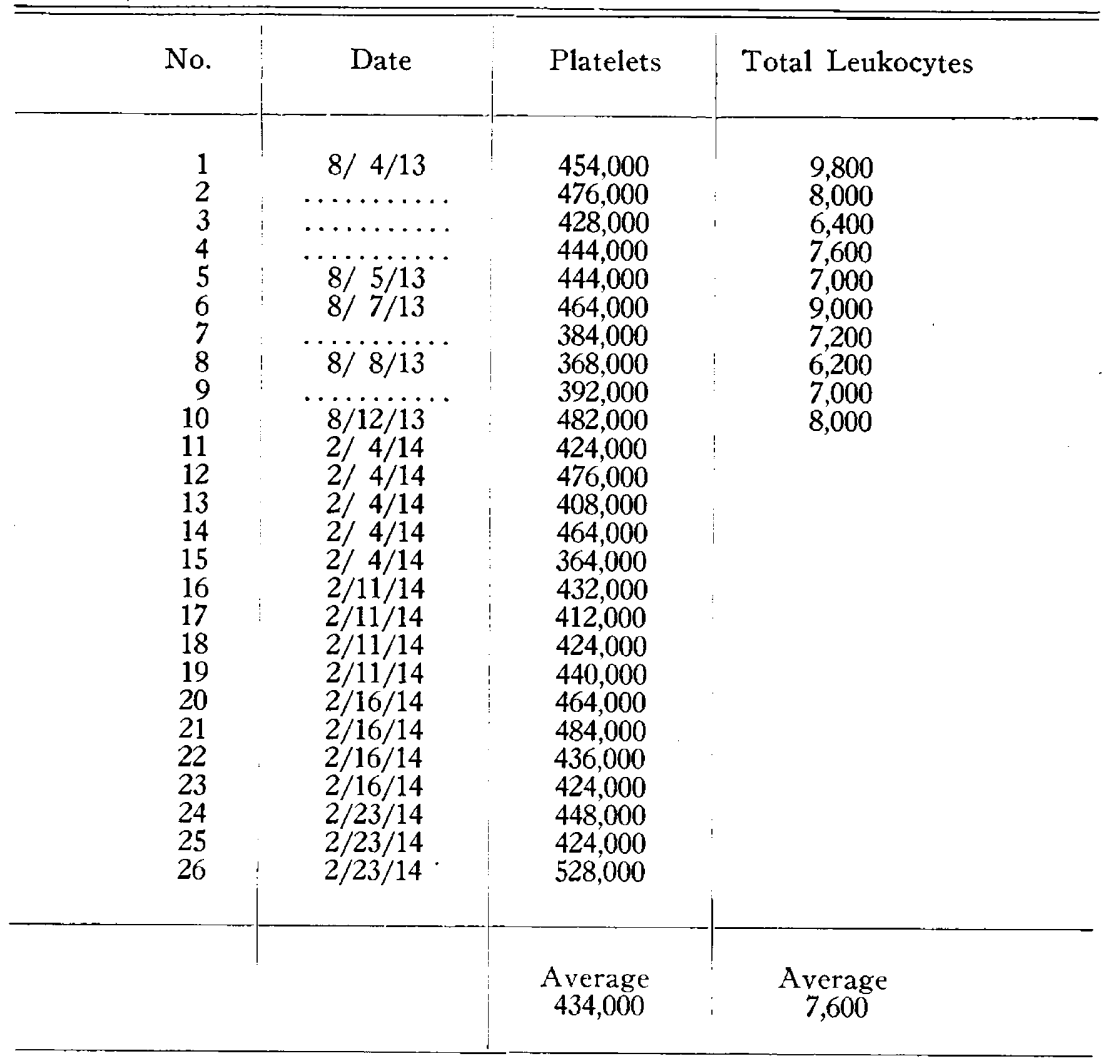

Table 5--Blood-Platelet Count in Tuberculous Guinea-Pigs at Colorado Springs, Col.

\begin{tabular}{r|r|r|r}
\hline No. & Date & Platelets & Total Leukocytes \\
\hline & & & \\
\hline 1 & $7 / 24 / 13$ & 696,000 & 14,000 \\
2 & $7 / 24 / 13$ & 760,000 & 13,000 \\
3 & $7 / 25 / 13$ & 724,000 & 12,000 \\
4 & $7 / 25 / 13$ & 604,000 & 11,000 \\
5 & $7 / 25 / 13$ & 576,000 & 12,000 \\
6 & $8 / 12 / 13$ & 612,000 & 11,000 \\
7 & $8 / 12 / 13$ & 776,000 & 10,000 \\
8 & $8 / 13 / 13$ & 492,000 & 11,000 \\
9 & $8 / 13 / 13$ & 540,000 & 11,000 \\
10 & $8 / 13 / 13$ & $596,000 *$ & 15,000 \\
11 & $8 / 13 / 13$ & $468,000 *$ & 12,000 \\
& & & \\
\hline & & & \\
& & Average & Average \\
& & 622,000 & 13,200 \\
\hline
\end{tabular}

* Counts 10 and 11 were made direct from jugular vein under ether. All others were made by cutting the pig's ear. 
It is conceded that Nature rarely operates without a purpose. Callus is not thrown out, as a rule, unless a bone is broken. In pneumonia we have generally a remarkable increase in the numbers of the polymorphonuclear leukocytes, the reason for which is better understood since Metchnikoff's studies in phagocytosis.

It has been recognized for some time that in several diseases, including tuberculosis, the blood-platelets become remarkably increased in number.

It is reasonable, therefore, to ask why do these elements increase, and do they take any part in immunity phenomena?

The microscope has never revealed their presence in the structure of tubercles, the formation of which is considered an immunity process. But other immunity processes are at work in the defense of the organism against the tubercle bacillus, for we know of the production of agglutinin, opsonin and, possibly, lysin and other immune bodies.

Table 6.-Blood-Platelet Count in Children Ill with Measles

\begin{tabular}{c|cc}
\hline \hline Case No. & Days Since Rash Appeared & Platelet Count \\
& & \\
\hline 1 & 4 & 248,000 \\
1 & 14 & 520,000 \\
2 & 16 & 292,000 \\
2 & 3 & 348,000 \\
3 & 7 & 260,000 \\
3 & 1 & 280,000 \\
4 & 5 & 276,000 \\
4 & 4 & 260,000 \\
5 & & 290,000 \\
$6^{*}$ & & \\
\end{tabular}

* An adult tuberculous patient. The tuberculosis pursued a rapid course following this attack of measles.

It is natural to ask, then, if Nature increases the blood-platelets in the victim of tubercle infection; is it for a purpose comparable with that found by Grüber and Futaki in rabbits or rats infected with anthrax?

Metchnikoff has maintained that antibodies, such as opsonins, are set free from leukocytes when these cells disintegrate. It is thought that serum as opposed to blood-plasma is very rich in opsonins, yet the work of Dastre ${ }^{14}$ proves that the white corpuscles are not disintegrated when blood coagulates.

The thought occurred, therefore, can platelets furnish opsonin? The experiments shown in Table 7 , several times carefully and thor-

14. Dastre, quoted by Aynaud: Le globulin de l'homme, Ann. de l'Inst. Pasteur, January, 1911. 
oughly repeated, certainly suggest that they can. The table presents a composite picture of the results of five careful and complete experiments.

Similar experiments were carried out with similar results with staphylococci, so that it is not impossible that blood-platelets contain or supply opsonin.

For these and the subsequent experiments, the platelets were obtained by fractional centrifugation in citrated normal salt solution. It was well known to those who worked with the opsonic index that the fitud remaining after throwing down the corpuscles by means of the centrifuge, contained platelets. This fluid was now removed by a pipet and centrifuged at a high speed. A faint sediment was thrown down and the supernatant fluid withdrawn. This sediment was twice washed and centrifuged with normal salt solution. The final sediment was found to consist of almost entirely pure blood-platelets. We have pointed out ${ }^{13}$ elsewhere that vagaries in the opsonic index might partly depend on the amount of platelets the washed corpuscles contained.

TABLE 7.-Composite Resllts of Authors' Experiments with BloodPlatelets and Tubercle Bacilli

\begin{tabular}{l|c|c|c|c}
\hline & $\begin{array}{c}\text { Polymorpho- } \\
\text { nuclears }\end{array}$ & $\begin{array}{c}\text { Large } \\
\text { Mono- } \\
\text { nuclears }\end{array}$ & $\begin{array}{c}\text { Percentage of Empty Cells } \\
\text { Polymorpho- } \\
\text { nuclears }\end{array}$ & $\begin{array}{c}\text { Large } \\
\text { Mono- } \\
\text { nuclears }\end{array}$ \\
\hline $\begin{array}{l}\text { Serum* ..... } \\
\text { Thick platelet } \\
\text { emulsion... }\end{array}$ & 1.05 & 0.83 & 26 & 29 \\
$\begin{array}{c}\text { Salt solution* } \\
\text { _. }\end{array}$ & 0.59 & 1.33 & 18 & 20 \\
\hline
\end{tabular}

* With tubercle bacilli emulsion and white corpuscues.

Experiments were undertaken in June, 1913, to ascertain if the addition of platelets to tubercle bacilli might prevent infection when inoculated simultaneously into a guinea-pig. The culture employed was later found to be dead and so the tests were worthless.

We have shown repeatedly that the subcutaneous inoctlation of a definite number of very virulent bacteria (50 tubercle bacilli of a culture from which 10 bacilli have been found to cause infection), isolated by the Barber technic, will almost invariably cause infection, and such infection is always accompanied first by enlargement and infection of the adjacent lymph-nodes. We have made it a rule to inoculate always into the nipple area so that subsequent enlargement of the groin glands can be readily detected; usually after the second week. 
It has frequently happened with these small doses that no local lesion has developed, but in animals so inoculated we have so far never missed the glandular involvement when the pigs have later been found tuberculous at necropsy.

The following experiments would, therefore, seem unusual:

Four young guinea-pigs were inoculated in the right nipple area.

Pig 1, weight $255 \mathrm{gm}$., received 200 tubercle bacilli.

Pig 2, weight 212 gm., received 200 tubercle bacilli + platelets from normal pig after incubation one-half hour.

Pig 3, weight $214 \mathrm{gm}$., received 200 tubercle bacilli.

Pig 4, weight $183 \mathrm{gm}$., received 200 tubercle bacilli + platelets from normal pig after incubation one-half hour.

Air was blown in following the injection in all except Pig 3. Forty-two days later Pig 1 was killed. No local tuberculous lesion; glands enlarged in right groin; extensive infection of spleen; mediastinal glands infected; extensive disease in liver. Thirty-four days later Pig 2 died of epidemic intestinal disease. One caseous nodule was found in the spleen. Nothing else was found, no local lesion and no groin glands infected. Forty-four days later Pig 3 was killed. No disease was found. It is probable that the bacteria were not safely inoculated. Forty days later Pig 4 died. No local lesion. No local glands in groin involved; extensive tuberculous infection in liver and spleen and mediastinal gland enlarged.

The chief interest of this experiment would seem to be in the absence of infection of the groin glands in Pigs 2 and 4 .

This absence of local glandular infection is most unusual and possibly might suggest a sensitizing of the bacilli by the platelets allowing a more general distribution in the system.

We have found in earlier experiments that 60 bacilli of this virulent culture will produce rapid and wide-spread lesions in such young guinea-pigs as well as infection of the glands adjoining the site of inoculation.

The following experiments deal with older guinea-pigs, usually full-grown. The injection in all animals was made in the right nipple area.

Dec. 29, 1913: Pig 53; 200 tubercle bacilli. Pig 54; 200 tubercle bacilli with human platelets. Pig 55; 200 tubercle bacilli with human platelets and inactive serum. Pig $56 ; 200$ tubercle bacilli with active (human) serum.

Jan. 18, 1914: Pig 55 has enlarged hard gland right groin. Others negative.

Feb. 16, 1914: Pig 56 has enlarged hard gland right groin.

April 11, 1914: Pig 55, killed. Enormous tuberculous liver and spleen; lungs completely involved (local lesion and glands had been previously removed).

April 23, 1914: Pig 53 gave birth to two young three weeks ago. Killed; no tuberculosis discovered. It is probable the bacilli were not safely inoculated.

April 23, 1914: Pig 56 gave birth to two young two weeks ago. Killed. Tuberculous spleen, few tubercles in liver, local gland, mediastinal gland.

April 17, 1914: Pig 54 has not yet shown infection. It is possible that bacilli were not safely inoculated. Fifty bacilli of same culture were now inoculated into left nipple area and also into a control, Pig 86. 
May 23, 1914: Pig 54, killed. Spleen markedly tuberculous, bronchial gland and deep inguinal gland, left side affected. No local lesion. Pig 86, killed. Spleen and bronchial glands affected. No local lesion.

This last experiment indicates that if the 200 bacilli were originally safely inoculated, immunity was not produced sufficiently to protect the pig later against 50 tubercle bacilli.

The foregoing experiments were repeated with the same virulent culture, but instead of human blood-platelets, "immune" platelets from another pig and scrum of this pig were employed.

Jan. 12, 1914. Pig 57, weight 565 gm.; 200 tubercle bacilli injected. Pig 58 , weight $555 \mathrm{gm}$.; 200 tubercle bacilli injected, + platelets taken from a guineapig with advancing tuberculosis. Pig 59, weight $437 \mathrm{gm}$.; 200 tubercle bacilli injected; serum unheated; platelets taken from a guinea-pig with advancing tuberculosis. Pig 60, weight $513 \mathrm{gm}$.; 200 tubercle bacilli; serum heated to 55 C. for one-half hour; platelets taken from a guinea-pig with advancing tuberculosis.

All the pipets were incubated with their contents one-half hour before inoculations were made.

Feb. 7, 1914: Pig 60, large gland palpable in right inguinal region.

Feb. 12, 1914: Pig 57, large gland palpable in right inguinal region.

Feb. 14, 1914: Pig 59, large gland palpable in right inguinal region.

Feb. 16, 1914: Pig 58, no enlarged glands palpable.

April 3, 1914: Pig 57, local inguinal glands stationary or smaller. Pig 58, no local enlarged glands. Pig 59, local glands increasing in size. Pig 60, local glands very large.

April 8, 1914: Pig 57, found dead; extensive tuberculosis of liver and spleen; large mediastinal glands; local glands had diminished in size recently and no tuberculosis was found.

April 25, 1914: Pig 59, killed. Extensive tuberculosis of spleen; moderate infection of lungs and liver; mediastinal glands very large; local inguinal glands enlarged.

April 25, 1914: Pig 60, killed. Moderate tuberculosis of spleen. Scattered nodules in lungs and liver. Mediastinal glands very large. Local inguinal glands palpable.

May 16, 1914: Pig 58, found dead. No tuberculous lesion anywhere. Death due to epidemic gastro-enteritis. It is, of course, again possible that the bacilli were not safely inoculated.

We realize that not enough experiments have yet been carried out and that the work is incomplete. We may, however, consider that:

1. It is suggestive that when a small amount of a thick emulsion of platelets is added to a lethal dose of virulent tubercle bacilli, infection would seem to be either modified or prevented.

2. When serum is added to this mixture, no evidence can be shown of any change in the infection produced from that of the controls.

\section{CONCLUSIONS}

1. Blood-platelets are consistently increased in the tuberculosis of man and guinea-pigs. 
2. At an altitude of 6,000 feet, blood-platelets are increased in the circulating blood of man and guinea-pigs.

3. Blood-platelets would appear either to contain or to supply opsonin.

4. Blood-platelets added to a lethal dose of tubercle bacilli appear to modify the course of infection or to prevent it.

5. The addition of serum to a mixture of blood-platelets and tubercle bacilli appears to interfere with this modification.

The foregoing work was aided by a grant from the American Medical Association to Dr. Gerald B. Webb.

Our grateful thanks are due Mr. and Mrs. B. C. Allen and Mr. Richard F. Howe for generous financial assistance.

1222 North Cascade Avenue-817 North Cascade Avenue. 